\title{
The Empirical Research of Transportation Infrastructure Investment and Economic Growth: Based on the Panel Data of "new silk road"
}

\author{
Chaoji Yang ${ }^{1, a}$ and Haiying $\mathrm{Ma}^{2, \mathrm{~b}^{*}}$ \\ ${ }^{1,2}$ School of Economics, Northwest University for Nationalities, Lanzhou (730124), P.R. China \\ a76580030@qq.com, blxmahaiying8888@163.com \\ ${ }^{*}$ The corresponding author
}

\begin{abstract}
Keywords: "New silk road" economic belt; Cointegration analysis; Transportation infrastructure
\end{abstract}
\begin{abstract}
In the Eurasian countries decided to create a new silk road. The Chinese government paid great importance to the development of the new silk road, and the academia pay attention to study on the relationship between the traffic infrastructure investment and economic growth in the macro level data. We apply the dynamic econometrics co-integration theory, by using 1986-2013 data of transport infrastructure of the western five provinces (Shanxi, Gansu, Ningxia, Qinghai, Xinjiang) in the new silk road economic belt, to present on the empirical analysis of the relationship between infrastructure investment and economic growth. The results show that the transportation infrastructure investment and economic growth maintained a long-term co-integration relationship.
\end{abstract}

\section{Introduction}

The "Silk road" proved a profound historical significance in the process of human economic and cultural exchange, and played an important role of transportation artery in international stages. In the 21 st century, the once-thriving traffic arteries compared with other channels, has featured a lot. Along the cities are located in China's inland hinterland, the business travel in history of city has abundant oil, natural gas, minerals and other precious natural resources, due to long-term backward transport infrastructure, results in the stagnation of the regional economic development. The glorious ancient silk road has become the bottleneck restricting the development of contemporary western region, it plagued serious foreign trade in the region between China and central Asia in the formation of an economic depression belt. The Eurasian economic in 2007 created new silk road of the golden path plan on the agenda. Renaissance Eurasian countries decided to invest $\$ 19.2$ billion. This article is to make a great contribution to human civilization economic artery. The Twelfth five-year regional harmonious development during an important period, in-depth analysis of the new silk road economic belt the dynamic relationship between transportation infrastructure investment and economic growth, solving such problems has important theoretical and practical significance.

Until the $1940 \mathrm{~s}$, foreign scholars is not going to be the infrastructure investment as a variable is introduced to analyze the economic growth, but investment in infrastructure and technology, political factors together due to the variable. After the 1940s, Boarnet firstly put forward such as infrastructure investment should be analyzed as one of the factors of economic growth. Aschauer (1987) first introduces infrastructure investment as the endogenous variable output model, the transportation infrastructure is obtained conclusions have important effect on economic growth, kicked off the entire infrastructure elasticity estimates from the 90s boom. Aschauer (1989) the government infrastructure investment to the private sector as the research object, the influence of output that infrastructure investment. The increase led to the growth of the economy with infrastructure to output (GDP) effect as object of research shows that economic growth led to increased infrastructure capital.

Domestic scholars about research lay particular stress on infrastructure investment is introduced in the $1980 \mathrm{~s}$ and the introduction of foreign theories, earlier research literature Shen (2002) compiled on Soviet research infrastructure and economic growth. Liu (2005) by studying the promoting effect on economic growth of the infrastructure investment model of dynamic econometric model using error correction model and the quantitative analysis of China discussed eastern, central and western regions 
infrastructure pushing effect on economic growth and analyzed the infrastructure investment elasticity of GDP, the greater its elasticity, it promote the more efficient. It concluded that infrastructure investment plays an important role in the national economy and can greatly stimulate the growth of GDP through traffic investment to China Zhang (2007). Infrastructure level and study of the relationship between regional economic growth reveals the level of transportation infrastructure and the relationship between the regional economic growth in China, and discusses the traffic leading role in the rise of central China. Qian (2007) using the cointegration test to 1980-2005 in China logistics development level, investment in fixed assets and GDP annual economic data are analyzed, and pointed out that there is a long-term and stable relationship.

\section{The Empirical Analysis}

Variable Selection. GDP is the measure of a country or region's economic level of the important indicators and methods, it refers to a country or a region all the permanent units in a year the value of the final results of the production activities form. With GDP as explanatory variables. According to the China statistical yearbook in the definition of statistical index of the transportation industry, this article selects the transportation infrastructure investment includes transportation, warehousing, postal service infrastructure investment. In Shaanxi, Gansu, Qinghai, Ningxia, Xinjiang five provinces of the transportation infrastructure investment as the explained variable, expressed in the TR.

The Model and Data. As the most economic time series is stable, if the directly to the non-stationary time series as a stationary time series of regression analysis, it may lead to undesirable consequences, such as pseudo regression problems, at the time of using time series analysis problem, the first thing you need to test time series is stable, at present the most commonly used method is the unit root test. Then analysis of economic growth and whether there is a cointegration relationship between the traffic infrastructure investment, when and only when more than one with cointegration between non-stationary variables, set up by these variables regression model to be meaningful, has a co-integration relationship between non-stationary variables can be used to establish the error correction model. Due to the error correction model combine long-term relationship and short-term dynamic characteristics in a model, so can not only overcome the traditional econometric models ignore the problem of spurious regression, and can establish a difference models ignore the weakness of level variable information.

In this paper the data from China statistical yearbook data from 1986-2013, and has been converted into the values calculated by the constant 1985, thereby eliminating the influence of the fluctuations in price change. In order to eliminate heteroscedasticity, GDP and TR has carried on the logarithmic transformation respectively.

ADF Test. As you can see in Table 1, GDP and TR ADF threshold values were greater than $1 \%$ levels to accept the null hypothesis, namely that time series is stationary. After first order difference, ADF statistics are less than $1 \%$ significance level, the critical value, which rejected the null hypothesis, that time series is stationary. In other words, GDP, TR is the first order list the whole sequence, it can be used in the cointegration test.

Table 1 ADF unit root test

\begin{tabular}{cccccc}
\hline \multirow{2}{*}{ Variables } & \multirow{2}{*}{ ADF Value (t stasistics) } & $\begin{array}{c}\text { Test Type } \\
\end{array}$ & \multirow{2}{*}{ Critical value } & \multirow{2}{*}{ P value } & \multirow{2}{*}{ Results } \\
\hline LNGDP & -2.006807 & $(\mathrm{c}, 0,0)$ & -3.711345 & 0.2822 & non-stable \\
\hline LNTR & -0.839209 & $(\mathrm{c}, 0,0)$ & -3.654334 & 0.7915 & non-stable \\
\hline DLNGDP & -4.081198 & $(\mathrm{c}, 0,0)$ & -3.859574 & 0.0045 & stable \\
\hline DLNTR & -5.103526 & $(\mathrm{c}, 0,0)$ & -3.975643 & 0.0002 & stable \\
\hline
\end{tabular}

Cointegration Test. In order to prove the non-stationary whether contains the long-term stable equilibrium relationship between variables, the cointegration test is required taking section E-G two-step on LNGDP and LNTR cointegration test. 
(1) using the least square method to first LNGDP and LNTR time series regression analysis, get the following equation:

$$
\begin{array}{cc}
\text { LNGDPt }=9.265+0.225 \mathrm{LNTRt} \\
\mathrm{T}=170.1496 & 17.7016 \\
\mathrm{R}^{\wedge} 2=0.923382 & \mathrm{DW}=1.342268
\end{array}
$$

Analysis of goodness of fit. According to an affirmative coefficient $\mathrm{R}^{\wedge} 2$, you can see that the fit of the linear regression model is very high, that will be very well all the data fitting on a straight line. Significance test. From the regression result shows that under the condition of the 5\% significant level, $T$ value significantly and the critical value, reject the null hypothesis, significant coefficient is not zero. Since the relevant inspection. This article USES the DW test through the look-up table, table tennis, when $\mathrm{n}=28, \mathrm{k}=1, \mathrm{DL}=1.328, \mathrm{Du}=1.476$, under $5 \%$ significance level, the model does not exist autocorrelation.

(2) the residual series stationarity test

As you can see the test result of the table 2, under $10 \%$ significance level, ADF value is less than the critical value, to reject the null hypothesis, shows that there is no unit root, residual sequence is stationary series, shows that the long-term equilibrium between GDP and the TR cointegration relationship.

Table 2 The results of the Estimation of Error Correction Model

\begin{tabular}{cccccc}
\hline \multirow{2}{*}{ Variables } & $\begin{array}{c}\text { ADF Value } \\
\text { stasistics })\end{array}$ & $\begin{array}{c}\text { Test } \\
\text { Model }\end{array}$ & Critical value & P value & Results \\
\cline { 3 - 4 } & -1.944435 & $(\mathrm{C}, \mathrm{T}, \mathrm{L})$ & & \\
\hline et & $-1.0,0)$ & -1.608593 & 0.0512 & stable \\
\hline
\end{tabular}

Error Correction Model. Cointegration test of equation reflects the long-term equilibrium relationship between the two, and the long-term equilibrium is implemented by short-term fluctuations continuously adjust and long-term cointegration equations of equilibrium will be short-term disequilibrium state back to equilibrium. The short and long-term adjustments can be made of error correction model to reflect, therefore the long-term equilibrium model of residual error sequence in as explanatory variables, it is concluded that the error correction model is as follows:

$$
\begin{aligned}
& \text { DLNGDPt }=0.0595-0.0162 D L N T R t+0.0421 \xi \mathrm{t}-1 \\
& \mathrm{~T}=4.343926 \quad 2.484682 \quad-3.271222 \\
& \mathrm{R}^{\wedge} 2=0.453266 \quad \mathrm{~F}=6.632342
\end{aligned}
$$

The estimated results show that the change of the gross domestic product (GDP) depends not only on the change of the transportation infrastructure investment, but also depends on the issue of gross domestic product to deviate from the equilibrium level, estimate of the error term factor t-1 reflects the deviation correction coefficient of 0.0421 , the greater the amount of this correction, it refers to the system error correction mechanism with large deviation.

\section{Conclusions}

Taking on the "silk road" economic belt in western province as samples, we analyzed the influence of transportation infrastructure investment to economic growth, the driving factor in the five provinces of western transportation infrastructure investment to GDP is a significant role in promoting. The economic belt in the Silk road of the traffic infrastructure construction and China's economic growth has the long-term stable equilibrium relationship, transportation infrastructure investment to promote economic growth. In the construction of "silk road" economic belt of the macro background, it is necessary to increase the traffic infrastructure investment of western provinces and regions. Based on the above conclusions, combining with the actual situation of silk road economic belt provinces, the area of traffic infrastructure construction has made the following policy suggestions. 
First, building up the government-led operating mechanism, adjusted by the market efficient transportation infrastructure investment. There are located in the silk road of several western provinces and the regional economy is weak in economic foundation, the folk investment is not active, so the pure market behavior does not solve the problem of insufficient funds. And too much rely on state funding, easy to cause problems such as inefficient, non-conducive to long-term development. So we can use special policies to attract domestic and foreign development main body joint investment and cooperation. At the same using form such as BOT to attract foreign capital or private capital of the eastern developed areas.

Second, setting up the scientific planning and building the efficient system of comprehensive transportation network. According to the analysis of this article, the traffic infrastructure construction of the driving effect on economic growth is increasing for a long time, but in the early stages of the investment is not significant, therefore, railway, highway, underground pipes and the layout of the air passage, and the choice of transport hub cities need to think about the longer term, the other is located in the special ecological area in northwest China, fragile ecological environment, the traffic infrastructure construction also need to consider environmental factors as far as possible with low energy consumption and high technology of green transportation.

\section{References}

[1] Zhang xueliang: China's transportation infrastructure investment and economic growth area comparative analysis, Journal of financial research, 8(2008)102-110.

[2] Ramanathan R. The Long-run Behavior of Transport Performance in India: A Co -integration Approach. Transportation Research, 5(2001)309-320.

[3] Holtz -Eakin D.Public sector capital and the Productivity Puzzle. Review of Economics and Stati stics, 1994.

[4] P. Cantos, M. Gumbau Albert, J.Maudos. Transport Infrastructures, Spillover Effects and Regional Growth: Evidence of the Spanish Case.Transport Reviews, 25(2005)25-50.

[5] Zhang Xueliang. Transport infrastructure, spatial spillover and the regional economic increase. Nanjing: Nanjing University Club, 5(2009)78-86.

[6] Bing-Lian China's transportation and regional economic development: an empirical study of causation. China Soft Science, 6, (2005)101-106.

[7] Zhang Di, The findings of a study of economic growth and the transportation facilities demand. Journal of Nanjing institute of statistics, 8 (2008) 87-90.

[8] Liu Xuehua, Zhang xueliang, Transport infrastructure investment and the interaction between the regional economic growth. Metropolitan area of research and development, 4(2009) 57-61.

[9] Wang Linxin, An empirical analysis of the transportation industry and economic growth in shandong province. Journal of shandong traffic institute, 2(2006)112-132.

[10]Zhao Dawei, Transportation and postal and telecommunication services and causation of the development of national economy. Journal of Dalian maritime university, 4 (2005)34-45.

[11] Wu Xiongbin, Highway traffic volume forecasting model based on neural network and its application. Journal of Fujian agriculture and forestry university, 2007.

[12] Wang Linxin. An empirical analysis of the transportation industry and economic growth in shandong province. Journal of Shandong traffic institute, 2(2006)87-85.

[13] Cheng Wenming, Green logistics environment of railway development opportunity. Railway transport and economy, 8(2003)91-102. 
